\title{
Symptom burden in geriatric hospitalized ESRD patients: Quantifying symptoms to increase nephrologist awareness and use of palliative care consultation
}

\author{
Jawed $\mathrm{A}^{1 *}$, Moe $\mathrm{SM}^{2}$, Moorthi $\mathrm{RN}^{2}$, Torke $\mathrm{AM}^{3}$ and Eadon $\mathrm{MT}^{2}$ \\ ${ }^{1}$ Division of Nephrology, Department of Medicine, Wayne State University School of Medicine, USA \\ ${ }^{2}$ Division of Nephrology, Department of Medicine, Indiana University School of Medicine, USA \\ ${ }^{3}$ Indiana University (IU) Center for Aging Research, Regenstrief Institute, IU School of Medicine, Charles Warren Fairbanks Center for Medical Ethics (FCME), \\ IU Health, IU Purdue University Indianapolis (IUPUI) Research in Palliative and End of Life Communication and Training (RESPECT) Center, Indianapolis, Indiana
}

\begin{abstract}
Importance: End Stage Renal Disease (ESRD) patients have significant symptom burden. Reduced provider awareness of symptoms contributes to underutilization of symptom management resources.

Objective: Assess symptom burden in patients with ESRD on dialysis. We hypothesized that improved nephrologist awareness of symptoms leads to symptom improvement.

Design, Setting and Participants: In this prospective, multicentre interventional study, 53 geriatric ESRD inpatients underwent symptom assessment using the modified Edmonton Symptom Assessment System (ESAS) at admission and 1-week post-discharge. Enrollers were sequentially randomized into 2 groups. The nephrologist of each individual was provided baseline symptom assessment in group 1 but was unaware in group 2 .

Main Outcomes and Measures: Severity ratings were compared between in-hospital and post discharge scores and between groups.

Results: 52 patients completed the study; 1 died. Baseline characteristics were compared. For $70 \%$ of the total cohort, physicians reported not being surprised if their patient died within a year. There was no difference in baseline scores between groups. Total ESAS scores improved more in group 1 (12.9) than group 2 (9.2) $(\mathrm{p}=0.04)$. Among individual symptoms, there was greater improvement in pain control $(\mathrm{p}=0.02)$, and nominal improvement in itching ( $\mathrm{p}=0.03)$ in $\mathrm{Group} 1$ as compared to Group 2. There were three palliative care consults.

Conclusions: Our findings reinforce the high symptom burden prevalent in geriatric ESRD patients. The improvement in total scores, and individual symptoms of pain and itching in group 1 indicates better symptom control when physician awareness is increased. Residual symptoms post hospitalization and low utilization of palliative care resources is suggestive of a missed opportunity by nephrologists to address the high symptom burden at the inpatient encounter which is selective for sicker patients and/or inadequacy of dialysis to control these symptoms.
\end{abstract}

\section{Background}

As the world population continues to age, a large number of nephrologists are faced with the question of dialysis and end of life care in the geriatric population. The SUPPORT study done in a large cohort showed pain, dyspnoea, anxiety and depression to be causing the greatest symptom burden in hospitalized patients [1]. Patients with End Stage Renal Disease (ESRD) have a significant burden of symptoms and mortality, approaching some cancers. Studies describe one-year mortality for octogenarians and nonagenarians after dialysis initiation as high as $46 \%$ [2]. However the use of hospice care and palliative medicine remains grossly underutilized [3].

Studies have demonstrated that renal providers' are largely unaware of their patient's symptom burden [4]. In addition, patients report having poor knowledge of palliative care options [5]. In an RCT of palliative care versus standard of care, patients randomized to Inpatient Palliative Care Service (IPCS) reported greater satisfaction with their care experience and providers' communication, had fewer ICU admissions on readmission, and lower total health care costs following hospital discharge; however, only $4 \%$ of patients had ESRD [6]. A previous study done on 19 patients with ESRD in an outpatient dialysis unit failed to show any benefit of palliative care intervention in terms of improvement in quality of life however it was thought to be limited due to the small sample size [7].

\section{Materials and Methods}

\section{Study population and setting}

We conducted a prospective cross-sectional study between October 2015 and May 2016 to compare symptom scores in hospitalized geriatric patients with ESRD at Indiana University Hospital, Eskenazi Hospital and Methodist Hospital in Indianapolis, Indiana. The Study

${ }^{\star}$ Correspondence to: Jawed A, Division of Nephrology, Department of Medicine, Wayne State University School of Medicine, USA, E-mail: jawed.areeba@gmail.com

Received: September 10, 2018; Accepted: September 25, 2018; Published: September 28, 2018 

consultation

was approved by the Institutional Review Board of the University (Figure 1).

\section{Survey design}

For symptom burden assessment, we performed the modified Edmonton Symptom Assessment (ESAS) upon admission and by phone call 1-week post-discharge (see appendix). The ESAS is a simple and widely used tool for measuring physical and psychological symptom distress. It consists of nine visual analogue scales, with a superimposed 0-10 scale for pain, activity/tiredness, nausea, depression, anxiety, drowsiness, appetite, well-being, and shortness of breath. The scale for each symptom is anchored by the words 'No' and 'Severe' at 0 and 10, respectively. A modified version containing an additional symptom of pruritus was validated against the Kidney Dialysis Quality of Life-Short Form (KDQOL-SF) questionnaire with an interclass coefficient of 0.7 [8]. The sum of the scores for all 10-symptom items was defined as the overall symptom distress score and ranged from 0 to 100 .

\section{Survey administration}

We administered the ESAS to all dialysis patients admitted to each of the three hospitals within 24 hours. The scores were sent to the attending Nephrologist and fellow within the same 24-hour period for EVERY OTHER patient, serving as a pseudo-randomized design. The attending nephrologist of alternating enrollees was provided the baseline score. Upon enrollment, all attending nephrologists were reminded of the availability of a palliative care consultation. The decision to consult was left to these clinicians and the hospital course was reviewed to determine whether inpatient palliative care was provided.

\section{Statistical analysis}

Patient level covariates gathered include: age of patient (years), gender $(\mathrm{M} / \mathrm{F})$, race, reason for ESRD, dialysis modality (In-centre HD/ Home $\mathrm{HD} / \mathrm{PD}$ ), dialysis vintage, access, presence of advanced directives on admission, admission diagnosis, and comorbid conditions including

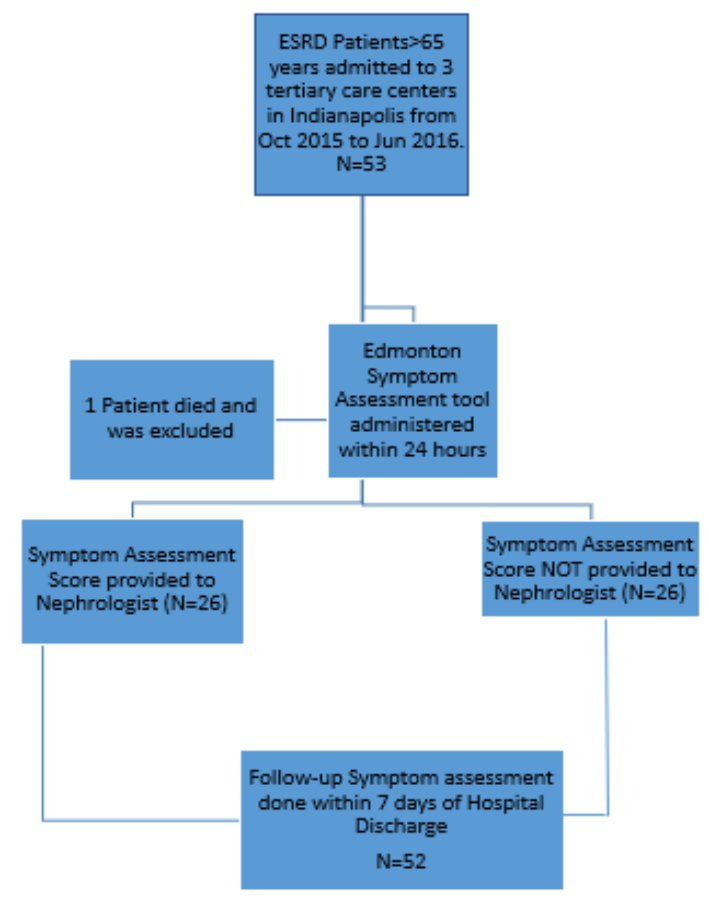

Figure 1. Study methods malignancy, CHF, DM, HTN, and COPD, duration of hospitalization, ICU admission. Baseline characteristic also included a score on the haemodialysis mortality predictor [9]. A descriptive statistical analysis was performed for all variables including mean +/- SD (normally distributed data), median and interquartile range (non-normal data), or number (\%) of patients (categorical variables). Baseline differences between the two groups were compared via a student's $t$ test or paired t-test (normal), or a chi-squared (categorical).

ESAS Scores for individual symptoms and total scores were compared between groups (those whose physicians were informed of score versus those who were not) via a student's $t$ test or paired t-test (normal). The absolute change in the total ESAS score, and each of the 10 symptom categories in patients whose physician was told score (Group 1) versus those whose physician was not told (Group 2).

\section{Results}

\section{Baseline characteristics}

A total of 53 patients were enrolled in the study of which 1 died and was excluded from further analysis. Mean (SD) age was 73.6 (7.09) years and $31(58.4 \%)$ patients were female. 47 (88.4\%) patients were on haemodialysis. Mean (SD) duration of hospitalization was 7.32 (5.45) days. In response to the question "would you be surprised if this patient died in the next 6 months" the physician answered yes for 19 patients $35.8 \%$. There were no baseline differences between the 2 groups other than the code status on admission. These characteristics are summarized in Table 1.

\section{Symptom assessment}

Baseline symptom assessment on admission to the hospital showed no difference between the 2 groups i.e. score unknown to nephrologist vs score known to nephrologist with the mean ESAS symptom score being highest for pain and fatigue (Table 2).

The absolute change in total score between assessment done on admission and following discharge was significantly different between the 2 groups $(p=0.04)$ showing greater improvement in symptoms following discharge when the nephrologist was made aware of the assessment (Table 3.1). Similarly, there was also noted a significant difference in absolute change in individual symptom score of pain $(\mathrm{p}=0.02)$ and itching $(\mathrm{p}=0.03)$ between the 2 groups (Table 3.2$)$

The mean scores for the total cohort did improve for each individual symptom with all $\mathrm{p}$ values $<0.05$ (Table 4.1). Individual symptom scores were also assessed between the 2 groups (Table 4.2). In Group 1 all symptoms showed improvement following discharge other than depression, nausea, anxiety and itching. Similarly, in Group 2 , all symptom scores were significantly lower at the post discharge assessment other than anxiety and sense of wellbeing.

\section{Discussion}

Our findings suggest that ESRD patients who are admitted to the hospital have a high symptom burden that may be unexpected based on the presenting complaint. Current management approaches could fail to identify these symptoms and adequately address them. This is evidenced by the multitude of symptoms that persisted after hospitalization in our study, including nausea, itching, depression, anxiety and sense of wellbeing.

There are several reasons why this may be the case: 1) nephrology providers may not be aware of therapeutic options due to limited 
Jawed A (2018) Symptom burden in geriatric hospitalized ESRD patients: Quantifying symptoms to increase nephrologist awareness and use of palliative care consultation

Table 1. Baseline Characteristics

\begin{tabular}{|c|c|c|c|c|}
\hline Factor & Total Cohort $(\mathrm{n}=53)$ & Known $(n=27)$ & Unknown (n=26) & $P$-value \\
\hline Age & $73.6(7.09)$ & $72.81(6.7)$ & $74.46(7.4)$ & 0.28 \\
\hline Gender, F & $31(58.4 \%)$ & $14(51.9 \%)$ & $17(65.3 \%)$ & 0.31 \\
\hline \multicolumn{4}{|l|}{ Ethnicity } & \multirow{4}{*}{0.31} \\
\hline White & $24(45.2 \%)$ & $12(44.4 \%)$ & $12(46.1 \%)$ & \\
\hline African American & $27(50.1 \%)$ & $15(29.6 \%)$ & $12(46.1 \%)$ & \\
\hline Hispanic & $2(3.7 \%)$ & 0 & $2(7.6 \%)$ & \\
\hline \multicolumn{4}{|l|}{ ESRD Etiology } & \multirow{5}{*}{0.6} \\
\hline HTN & $15(28.3 \%)$ & $7(25.9 \%)$ & $8(30.7 \%)$ & \\
\hline $\mathrm{DM}$ & $28(52.8 \%)$ & $13(48.1 \%)$ & $15(57.6 \%)$ & \\
\hline GN & $4(7.5 \%)$ & $3(11.1 \%)$ & $1(3.8 \%)$ & \\
\hline $\mathrm{Oh}$ & $6(11.3 \%)$ & $4(14.8 \%)$ & $2(7.6 \%)$ & \\
\hline \multicolumn{4}{|l|}{ Modality } & \multirow{4}{*}{0.1} \\
\hline In center HD & $47(88.6 \%)$ & $26(96.2 \%)$ & $21(80.7 \%)$ & \\
\hline Home & $2(3.7 \%)$ & $1(3.7 \%)$ & $1(3.8 \%)$ & \\
\hline PD & $4(7.5 \%)$ & 0 & $4(15.3 \%)$ & \\
\hline Dialysis Vintage, Years & $5.06(5.1)$ & $5.61(5.98)$ & $4.48(4.04)$ & 0.42 \\
\hline \multicolumn{4}{|l|}{ Access } & \multirow{5}{*}{0.13} \\
\hline TDC & $19(35.8 \%)$ & $12(44.4 \%)$ & $7(26.9 \%)$ & \\
\hline AVF & $23(62.2 \%)$ & $11(40.7 \%)$ & $12(46.1 \%)$ & \\
\hline AVG & $7(13.2 \%)$ & $4(14.8 \%)$ & $3(11.5 \%)$ & \\
\hline PD catheter & $4(7.5 \%)$ & 0 & $4(15.45)$ & \\
\hline ADC on admission & $19(35.8 \%)$ & $10(37 \%)$ & $9(34.6 \%)$ & 0.85 \\
\hline \multicolumn{5}{|l|}{ Comorbid Conditions } \\
\hline $\mathrm{CHF}$ & $27(50.9 \%)$ & $13(48.1 \%)$ & $14(53.8 \%)$ & 0.67 \\
\hline $\mathrm{DM}$ & $35(66 \%)$ & $17(62.9 \%)$ & $18(69.2 \%)$ & 0.63 \\
\hline HTN & $52(98 \%)$ & $26(96.2 \%)$ & $26(100 \%)$ & 0.32 \\
\hline COPD & $7(13.2 \%)$ & $3(11.1 \%)$ & $4(15.3 \%)$ & 0.64 \\
\hline Malignancy & $6(11.3 \%)$ & $3(11.1 \%)$ & $3(11.5 \%)$ & 0.96 \\
\hline CAD & $27(50.9 \%)$ & $11(40.7 \%)$ & $16(61.5 \%)$ & 0.21 \\
\hline Vascular Disease & $19(35.8 \%)$ & $9(33.3 \%)$ & $10(38.4 \%)$ & 0.69 \\
\hline Duration of hospitalization (Days) & $7.32(5.45)$ & $7.74(4.73)$ & $6.88(6.17)$ & 0.6 \\
\hline Palliative Care Consult & $3(5.6 \%)$ & $1(3.7 \%)$ & $2(7.6 \%)$ & 0.52 \\
\hline Code Status, DNR & $8(15 \%)$ & $1(3.7 \%)$ & $7(26.9 \%)$ & $0.01 *$ \\
\hline Code Status on Discharge, DNR & $9(16.9 \%)$ & $2(7.4 \%)$ & $7(26.9 \%)$ & 0.06 \\
\hline ICU Transfer & $8(15 \%)$ & $6(22.2 \%)$ & $2(7.6 \%)$ & 0.12 \\
\hline $\begin{array}{l}\text { Advanced care Directives at } \\
\text { discharge }\end{array}$ & $20(37.7 \%)$ & $10(37 \%)$ & $10(38.4 \%)$ & 0.9 \\
\hline \multicolumn{4}{|l|}{ Discharge Outcome } & \multirow{5}{*}{0.36} \\
\hline Death & $1(1.9 \%)$ & 0 & $1(3.8 \%)$ & \\
\hline Discharge to home & $28(52.8 \%)$ & $15(55.5 \%)$ & $13(50 \%)$ & \\
\hline Discharge to facility & $23(62.2 \%)$ & $12(44.4 \%)$ & $11(42.3 \%)$ & \\
\hline Enrollment in Hospice & $2(3.8 \%)$ & 0 & $2(7.6 \%)$ & \\
\hline Albumin, g/dL & $3.0(0.56)$ & $3.0(0.51)$ & $3.02(0.62)$ & 0.97 \\
\hline Would the nephrologist be surprised, Yes & $19(35.8 \%)$ & $10(37 \%)$ & $9(34.6 \%)$ & 0.85 \\
\hline Dementia & $7(13.2 \%)$ & $3(11.1 \%)$ & $4(15.3 \%)$ & 0.64 \\
\hline \multicolumn{5}{|l|}{ In-Hospital Mortality in 60 days } \\
\hline $\begin{array}{l}\text { Estimated survival on dialysis in } \\
6 \text { months }\end{array}$ & $72.1(20.8)$ & $73.3(18.6)$ & $70.8(23.4)$ & 0.75 \\
\hline $\begin{array}{l}\text { Estimated mortality on dialysis in } \\
6 \text { months }\end{array}$ & $27.9(20.8)$ & $26.6(18.6)$ & $29.1(23.4)$ & 0.75 \\
\hline
\end{tabular}

Table 2. Baseline scores between the 2 groups

\begin{tabular}{|l|c|c|c|}
\hline Symptoms & ESAS Score unknown to nephrologist & ESAS Score known to nephrologist & P Value \\
\hline Pain & $5.38(3.6)$ & $5.7(3.4)$ \\
\hline Fatigue & $5.99(3)$ & $5.4(2.81)$ \\
\hline Drowsiness & $3.8(3.2)$ & $4.2(2.2)$ & 0.7 \\
\hline Nausea & $2.5(3.2)$ & $3.3(2.6)$ & 0.5 \\
\hline Lack of Appetite & $4.8(3.1)$ & $3.6(2.6)$ & 0.3 \\
\hline Shortness of breath & $4.7(2.7)$ & $5.4(3.2)$ & $3(3.3)$ \\
\hline Depression & $4(3.4)$ & $1.9(2.4)$ & 0.07 \\
\hline Anxiety & $2.6(3.1)$ & $5.11(2.6)$ & 0.5 \\
\hline Well Being & $5(2.04)$ & $4.3(3.7)$ & 0.4 \\
\hline Itching & $4.4(3.3)$ & 0.8 & \\
\hline
\end{tabular}


Jawed A (2018) Symptom burden in geriatric hospitalized ESRD patients: Quantifying symptoms to increase nephrologist awareness and use of palliative care consultation

Table 3.1. Absolute change in total score

\begin{tabular}{|l|l|l|l|}
\hline Total Score & $\begin{array}{l}\text { ESAS Score unknown } \\
\text { to nephrologist }\end{array}$ & $\begin{array}{l}\text { ESAS Score known to } \\
\text { nephrologist }\end{array}$ & P Value \\
\hline Change in total Score & 9.2 & 12.9 & $0.04^{*}$ \\
\hline
\end{tabular}

Table 3.2. Absolute change in each symptoms score

\begin{tabular}{|l|c|c|c|}
\hline Symptoms & $\begin{array}{c}\text { ESAS Score } \\
\text { unknown to } \\
\text { nephrologist }\end{array}$ & $\begin{array}{c}\text { ESAS Score known } \\
\text { to nephrologist }\end{array}$ & P value \\
\hline Pain & $0.96(1.97)$ & $2.37(2.28)$ & $0.02^{*}$ \\
\hline Fatigue & $1.2(1.25)$ & $1.33(2.1)$ & 0.8 \\
\hline Drowsiness & $1.44(1.8)$ & $1.8(1.7)$ & 0.55 \\
\hline Nausea & $0.4(1.6)$ & $1.1(1.3)$ & 0.08 \\
\hline Lack of appetite & $0.83(1.8)$ & $0.66(1.33)$ & 0.8 \\
\hline Shortness of breath & $2.3(1.5)$ & $3(1.8)$ & 0.11 \\
\hline Depression & $0.44(1.04)$ & $0.7(1.1)$ & 0.38 \\
\hline Anxiety & $0.32(0.85)$ & $-0.11(1.2)$ & 0.14 \\
\hline Well being & $1.08(1.35)$ & $0.7(2.3)$ & 0.5 \\
\hline Itching & $0.4(0.99)$ & $1.2(1.7)$ & $0.03 *$ \\
\hline
\end{tabular}

Table 4.1. Mean Scores for Total Cohort

\begin{tabular}{|l|c|c|c|}
\hline Symptoms & Baseline Score & Follow up Interview & p-value \\
\hline Pain & $5.6(3.5)$ & $3.9(2.3)$ & $<0.001^{*}$ \\
\hline Fatigue & $5.7(2.9)$ & $4.48(2.4)$ & $<0.001^{*}$ \\
\hline Drowsiness & $4.04(2.8)$ & $2.3(1.9)$ & $<0.001^{*}$ \\
\hline Nausea & $2.9(2.91)$ & $2.2(2.00)$ & $<0.001^{*}$ \\
\hline Lack of appetite & $4.07(2.9)$ & $3.4(2.5)$ & $0.001^{*}$ \\
\hline Shortness of breath & $5.07(3)$ & $2.5(1.7)$ & $<0.001^{*}$ \\
\hline Depression & $3.5(3.4)$ & $2.8(2.8)$ & $<0.001^{*}$ \\
\hline Anxiety & $2.3(2.8)$ & $2.2(2.7)$ & $<0.001^{*}$ \\
\hline Well being & $5.02(2.3)$ & $4.1(2.1)$ & $0.001^{*}$ \\
\hline Itching & $4.3(3.5)$ & $3.6(2.8)$ & $0.0002^{*}$ \\
\hline
\end{tabular}

Table 4.2. Individual symptom scores between the 2 groups

\begin{tabular}{|l|c|c|c|c|c|c|}
\hline ESAS Score unknown to nephrologist & \multicolumn{3}{|c|}{ ESAS Score known to nephrologist } \\
\hline Symptoms & $\begin{array}{c}\text { Baseline } \\
\text { Interview }\end{array}$ & $\begin{array}{c}\text { Follow up } \\
\text { interview }\end{array}$ & P value & $\begin{array}{c}\text { Baseline } \\
\text { Interview }\end{array}$ & $\begin{array}{c}\text { Follow up } \\
\text { Interview }\end{array}$ & P value \\
\hline Pain & $5.38(3.6)$ & $4.6(2.4)$ & $0.02^{*}$ & $5.7(3.4)$ & $3.3(2.09)$ & $<0.001^{*}$ \\
\hline Fatigue & $5.99(3)$ & $4.9(2.5)$ & $<0.001^{*}$ & $5.4(2.81)$ & $4.1(2.2)$ & $0.003^{*}$ \\
\hline Drowsiness & $3.8(3.2)$ & $1.9(2.1)$ & 0.005 & $4.2(2.2)$ & $2.5(1.7)$ & $<0.001^{*}$ \\
\hline Nausea & $2.5(3.2)$ & $2.2(2.4)$ & 0.24 & $3.3(2.6)$ & $2.1(1.6)$ & $0.0002^{*}$ \\
\hline $\begin{array}{l}\text { Lack of } \\
\text { appetite }\end{array}$ & $4.8(3.1)$ & $4.1(2.7)$ & $0.03^{*}$ & $3.6(2.6)$ & $2.7(2.1)$ & $0.01^{*}$ \\
\hline $\begin{array}{l}\text { Shortness } \\
\text { of breath }\end{array}$ & $4.7(2.7)$ & $2.6(1.7)$ & $<0.001^{*}$ & $5.4(3.2)$ & $2.3(1.7)$ & $<0.001^{*}$ \\
\hline Depression & $4(3.4)$ & $3.5(2.9)$ & 0.05 & $3(3.3)$ & $2.2(2.7)$ & $0.002^{*}$ \\
\hline Anxiety & $2.6(3.1)$ & $2.4(3.2)$ & 0.07 & $1.9(2.4)$ & $2.1(2.2)$ & 0.63 \\
\hline Well being & $5(2.04)$ & $3.9(1.6)$ & $<0.001 *$ & $5.11(2.6)$ & $4.4(2.5)$ & 0.11 \\
\hline Itching & $4.4(3.3)$ & $4.1(3)$ & 0.08 & $4.3(3.7)$ & $3.1(2.6)$ & $0.001^{*}$ \\
\hline
\end{tabular}

training in symptom management, 2) dialysis therapy itself does not provide the much-needed relief from these symptoms and 3) there is a sense of urgency during hospitalization to expedite discharge from the hospital which limits time to thoroughly evaluate these symptoms. Although we noticed an improvement in symptoms related to pain and breathing in both groups, there was greater improvement when the nephrologists were provided the ESAS results for their patients. This supports the idea that increased awareness of patient symptoms may result in increased use of therapeutic options available for pain in dialysis patients.

Despite providers saying they would not be surprised if the patient died within the next 6 months, we observed an extremely low rate of palliative care consultation. In the entire cohort, only three palliative care consults were received, and most patients remained full code at the time of discharge. Prior studies have shown that $99 \%$ of respondents agree that physicians have a responsibility to help patients at the end of life (EOL) and in preparing for death [10]. However, in their fellowship training, less than one-half of physicians were taught how to respond to a patient's request to discontinue dialysis therapy, conduct a family meeting about dialysis options, or determine when to refer patients to hospice or palliative care [10].

Our study has multiple strengths and limitations. The key limitation is its small sample size. This limitation is counterbalanced by its randomized nature, and pragmatic design including a variety of hospitals within our academic centre that provide renal care to diverse ESRD patients. Furthermore, our nephrology division is one of the biggest in the country, so this approach is reflective of a huge number of providers and offers generalizability to other centres.

\section{Conclusion}

In conclusion, our findings reinforce the high symptom burden prevalent in geriatric ESRD patients. Residual symptoms post hospitalization and low utilization of palliative care resources is suggestive of a missed opportunity by nephrologists to address the high symptom burden at the inpatient encounter which is selective for sicker patients and/or inadequacy of dialysis to control these symptoms.

\section{References}

1. Desbiens NA, Mueller-Rizner N, Connors AF, Wenger NS, Lynn J (1999) The symptom burden of seriously ill hospitalized patients. SUPPORT Investigators. Study to Understand Prognoses and Preferences for Outcome and Risks of Treatment. J Pain Symptom Manage 17: 248-255.

2. Kurella M, Covinsky KE, Collins AJ, Chertow GM (2007) Octogenarians and nonagenarians starting dialysis in the United States. Ann Intern Med 146: 177-183. [Crossref]

3. Kurella Tamura M, Cohen LM (2010) Should there be an expanded role for palliative care in end-stage renal disease? Curr Opin Nephrol Hypertens 19: 556-560. [Crossref]

4. Weisbord SD, Fried LF, Mor MK, Resnick AL, Unruh ML, et al. (2007) Renal provider recognition of symptoms in patients on maintenance hemodialysis. Clin J Am Soc Nephrol 2: 960-967. [Crossref]

5. Davison SN (2010) End-of-life care preferences and needs: perceptions of patients with chronic kidney disease. Clin J Am Soc Nephrol 5: 195-204. [Crossref]

6. Gade G, Venohr I, Conner D, McGrady K, Beane J, et al. (2008) Impact of an inpatient palliative care team: a randomized control trial. J Palliat Med 11: 180-190. [Crossref]

7. Weisbord SD, Carmody SS, Bruns FJ, Rotondi AJ, Cohen LM, et al. (2003) Symptom burden, quality of life, advance care planning and the potential value of palliative care in severely ill haemodialysis patients. Nephrol Dial Transplant 18: 1345-1352.

8. Davison SN, Jhangri GS, Johnson JA (2006) Cross-sectional validity of a modified Edmonton symptom assessment system in dialysis patients: a simple assessment of symptom burden. Kidney Int 69: 1621-1625.

9. Cohen LM, Ruthazer R, Moss AH, Germain MJ (2010) Predicting six-month mortality for patients who are on maintenance haemodialysis. Clin J Am Soc Nephrol 5: 72-79. [Crossref]

10. Combs SA, Culp S, Matlock DD, Kutner JS, Holley JL, et al. (2015) Update on endof-life care training during nephrology fellowship: a cross-sectional national survey of fellows. Am J Kidney Dis 65: 233-239.

Copyright: (C2018 Jawed A. This is an open-access article distributed under the terms of the Creative Commons Attribution License, which permits unrestricted use, distribution, and reproduction in any medium, provided the original author and source are credited. 